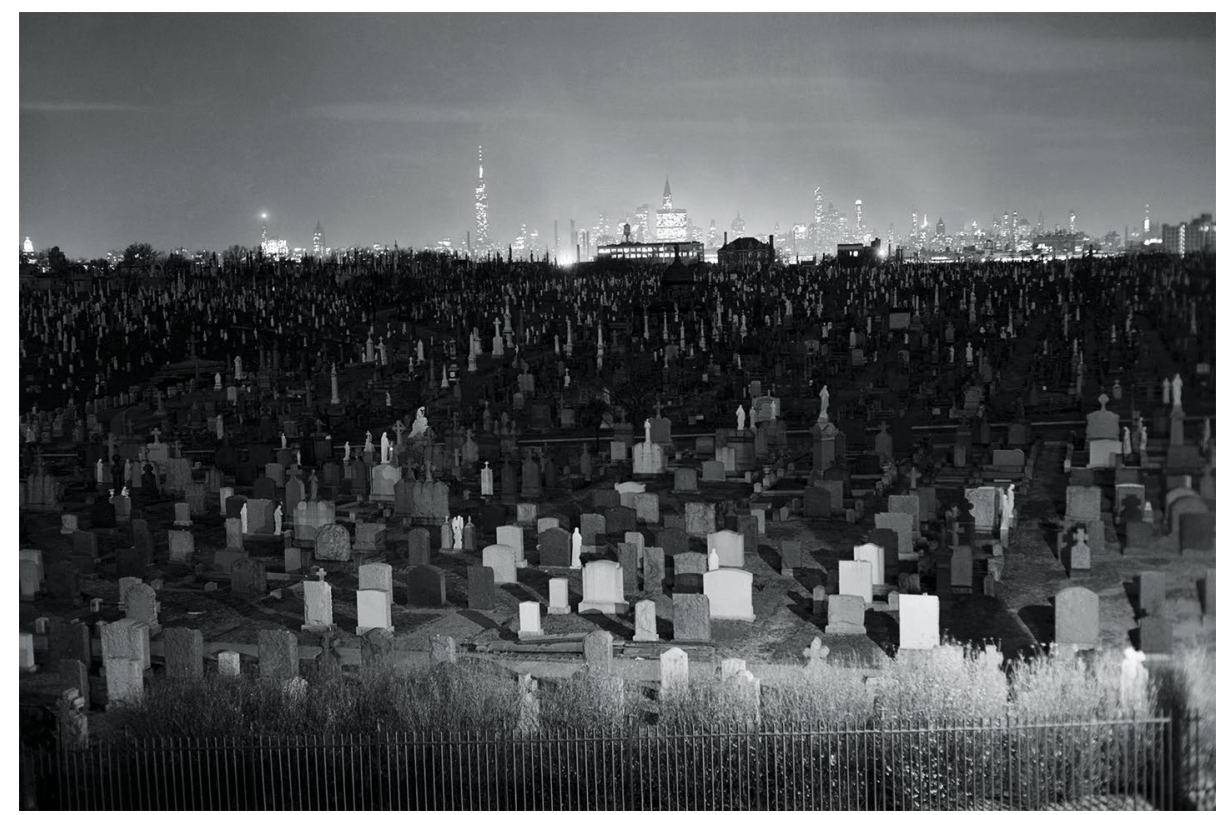

Credit: Bettmann / Getty images

While much recent discussion about the sustainability of death has focused on how 'green' methods like cremation are or can be, the fact remains that a significant portion of the land used by cemeteries remains a controversial topic in the scope of urban sprawl and liveability.

Zaheer Allam at Curtin University, Australia, examined not just how various religions approach the processing of those who have died, with their various requirements for taking care of the body, but also the pressure that such requirements put on urban land. Highlighting various cases around the world, especially Queens, New York, Allam addresses the morality and economics of land use that seems to prioritize the dead over the living; some 15 cemeteries house 5 million gravesites, while the rest of the borough is home to 2.4 million people who are experiencing increased gentrification and higher living costs. This discordance between the religious and moral views that hold these graves to be sacred and the argument that land should be used for the living through increased housing or park space is unlikely to abate soon, but the discussion is necessary for sustainable cities.

\section{Ryan Scarrow}

Published online: 11 September 2019

https://doi.org/10.1038/s41893-019-0383-2 